\title{
BMJ Open Epidemiological characteristics of elevated blood pressure among middle and high school students aged 12-17 years: a cross-sectional study in Jiangsu Province, China, 2017-2018
}

\author{
Xiyan Zhang, ${ }^{1}$ Jie Yang, ${ }^{1}$ Yan Wang,${ }^{1}$ Weina Liu, ${ }^{1}$ Wenyi Yang,${ }^{1}$ Liuwei Gao, ${ }^{1,2}$ \\ Rainer Schwertz, ${ }^{3}$ Andreas Welker, ${ }^{3}$ Fengyun Zhang, ${ }^{1}$ Yonglin Zhou ${ }^{1}$
}

To cite: Zhang $X$, Yang J, Wang $Y$, et al. Epidemiological characteristics of elevated blood pressure among middle and high school students aged 12-17 years: a cross-sectional study in Jiangsu Province, China, 2017-2018. BMJ Open 2019;9:e027215. doi:10.1136/ bmjopen-2018-027215

- Prepublication history and additional material for this paper are available online. To view these files, please visit the journal online (http://dx.doi. org/10.1136/bmjopen-2018027215).

Received 23 October 2018 Revised 13 June 2019 Accepted 11 July 2019

Check for updates

(c) Author(s) (or their employer(s)) 2019. Re-use permitted under CC BY-NC. No commercial re-use. See rights and permissions. Published by BMJ.

${ }^{1}$ Jiangsu Province Center for Disease Control and Prevention, Nanjing, China

${ }^{2}$ School of Public Health, Southeast University, Nanjing, China

${ }^{3}$ Local Health Authority RheinNeckar-Kreis, Heidelberg, Germany

Correspondence to Dr Fengyun Zhang; 434908934@qq.com

Dr Yonglin Zhou; jsepipublic@sina.com

\section{ABSTRACT}

Objective In this study, we aimed to present the epidemiological characteristics of elevated blood pressure among middle and high school students aged 12-17 years in Jiangsu Province.

Setting Hypertension, which is considered a rare disease in children, is an important early precursor to long-term cardiovascular damage, and elevated blood pressure in childhood is a strong predictor of hypertension in adulthood.

Participants Physical examination and questionnaire investigation among children aged 12-17 years in Jiangsu Province were conducted from 2017 to 2018.

Main outcome measures Physical measurements included height, weight, blood pressure and history of menarche/first spermatorrhoea. Questionnaire investigation included family type, delivery mode, lifestyle habits and psychological test.

Results In our study we investigated 17791 middle and high school students, consisting of 8701 female students and 9090 male students. The prevalence of screening elevated blood pressure among students aged 12-17 years was $20.0 \%$ (95\% Cl $19.2 \%$ to $20.9 \%$ ) for female students and $22.3 \%$ (95\% Cl $21.5 \%$ to $23.2 \%$ ) for male students. The prevalence of screening elevated blood pressure for urban male middle and high school students was higher than that of elevated blood pressure for rural male middle and high school students. However, similar phenomenon cannot be observed among female students. For both male and female students, body mass index (BMI), obesity/ overweight and menarche/first spermatorrhoea can be a risk factor contributing to elevated blood pressure, and sleep time and regional distribution might be important factors that need to be investigated in depth.

Conclusion We found a relatively high prevalence of screening elevated blood pressure among students aged 12-17 years for both female and male students in Jiangsu Province. The risk factors can be BMI, obesity/overweight and menarche/first spermatorrhoea.

\section{INTRODUCTION}

Hypertension or elevated blood pressure (BP) is an important risk factor for cardiovascular

\section{Strengths and limitations of this study}

- This is the first study to present the prevalence of elevated blood pressure among middle and high students in Jiangsu Province using the National Blood Pressure Reference for Chinese Han Children and Adolescents, and this study covers all 13 cities of Jiangsu Province.

- There is a relatively high prevalence of screening elevated blood pressure among students aged 12-17 years in Jiangsu Province.

- Body mass index, obesity/overweight, menarche/ first spermatorrhoea, sleep time and regional distribution might have an impact on this phenomenon.

disease, causing more than seven million deaths worldwide each year. ${ }^{1}$ It contributes to an increase in the lifetime risk of stroke or coronary heart disease death in Asian population. $^{2}$ Childhood hypertension, which is closely correlated with adulthood hypertension, does damage to the arteries of target organs such as the heart, brain and kidney. ${ }^{3-6}$

In China, a national survey indicated that the prevalence of hypertension was high, and that awareness, treatment and control rates did not match the fast economic development. ${ }^{7}$ We found that the increased trend in the prevalence of hypertension is striking in young people and rural populations. ${ }^{8}$ In the USA, hypertension and its unawareness are common in young adult population, and most participants with hypertension were unaware of their elevated BP. ${ }^{9}$ However, these studies did not reveal detailed information on people younger than 18 years of age, and a lot of reasons may contribute to this phenomenon. In this study we will describe the epidemiological characteristics of elevated BP 
among middle and high school students aged 12-17 years in China.

China is one of the world's largest developing countries with a population of 1.37 billion, and while the prevalence of elevated BP has been stable among Chinese children, this has become more and more concerning recently. ${ }^{3}{ }^{10}$ Located in eastern China, Jiangsu Province is one of the developed regions in the country. We have previously reported that the prevalence of overweight and obesity among primary school children was $15.2 \%$ (18.7\% for male students and $11.0 \%$ for female students) and $11.7 \%$ (14.5\% for male students and $8.2 \%$ for female students), respectively, and we found that obesity in children was closely associated with elevated BP. ${ }^{11}$ Therefore, in this study we intend to show more detailed information about the epidemiological characteristics of elevated BP among children and adolescents in Jiangsu Province.

Table 1 Baseline characteristics of middle and high school students aged 12-17 years in Jiangsu Province, 2017-2018

\section{Characteristics of female students} (8701)

\section{Age}

$12 \sim$

13

14

15

$16 \sim$

17

Mean \pm SD

Region

Rural

Urban

n (\%)/mean \pm SD

1133 (13.0)

1567 (18.0)

1539 (17.7)

1561 (17.9)

1539 (17.7)

1362 (15.7)

$14.6 \pm 1.6$

3555 (40.9)

5146 (59.1)

Physical examination

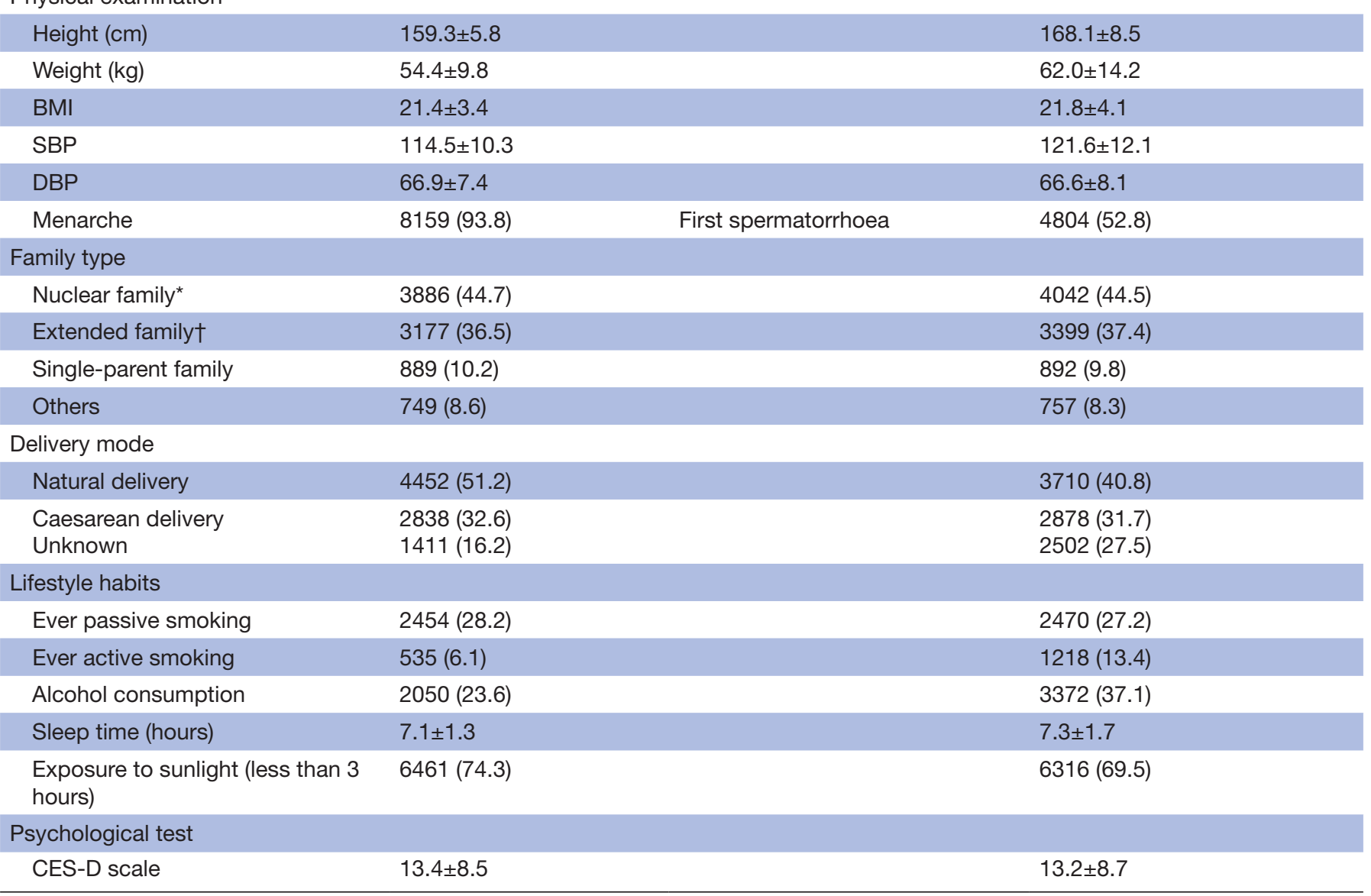

*Nuclear family: a family unit consisting only of a father, mother and children.

†Extended family: a network of relatives that include grandparents, cousins, uncles, aunts and foster children.

$\mathrm{BMI}$, body mass index; DBP, diastolic blood pressure; SBP, systolic blood pressure.
Characteristics of male students

(9090)

n $(\%) / m e a n \pm S D$

1104 (12.0)

$1660(18.3)$

1536 (16.9)

1634 (18.0)

1596 (17.6)

1560 (17.2)

$14.6 \pm 1.6$

3448 (37.9)

5642 (62.1)

$168.1 \pm 8.5$

$121.6 \pm 12.1$

$66.6 \pm 8.1$

$4042(44.5)$

$3399(37.4)$

$892(9.8)$

757 (8.3)

3710 (40.8)

$2878(31.7)$

$2502(27.5)$

$2470(27.2)$

$7.3 \pm 1.7$

6316 (69.5)

$13.2 \pm 8.7$ 
Table 2 Age-specific prevalence of screening elevated blood pressure among middle and high school students aged 12-17 years in Jiangsu Province, 2017-2018

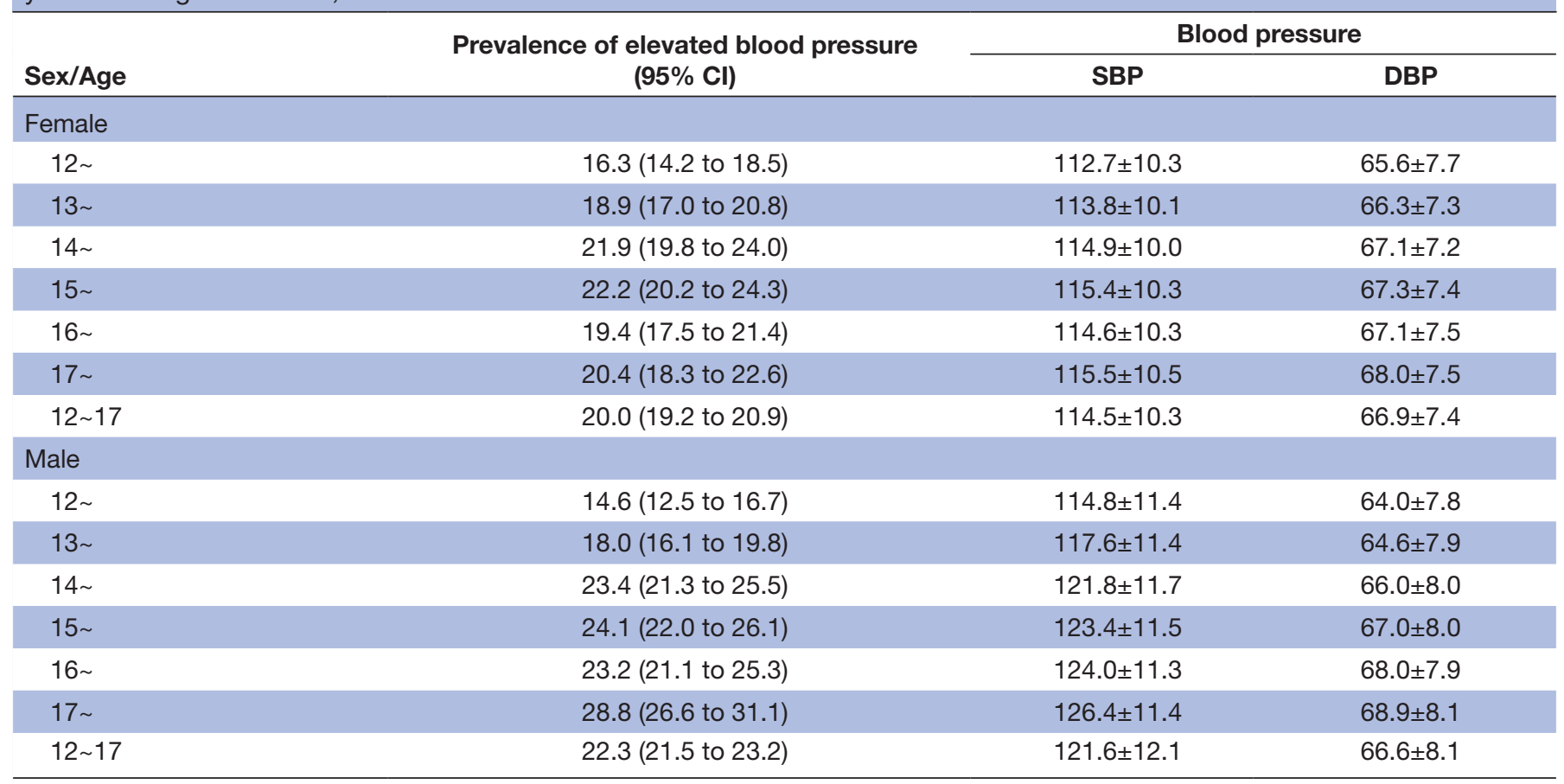

DBP, diastolic blood pressure; SBP, systolic blood pressure.

\section{METHODS}

\section{Setting and participants}

This study was based on the project 'Surveillance for common disease and health risk factors among students' in Jiangsu Province, which was conducted during the 2017-2018 academic year. We selected students aged 12-17 years from all 13 cities in Jiangsu Province, with
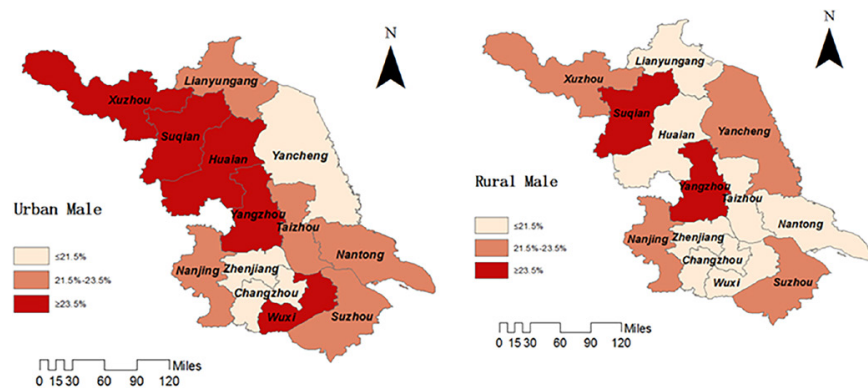

$\begin{array}{lllll}01530 & 60 & 90 & 120\end{array}$
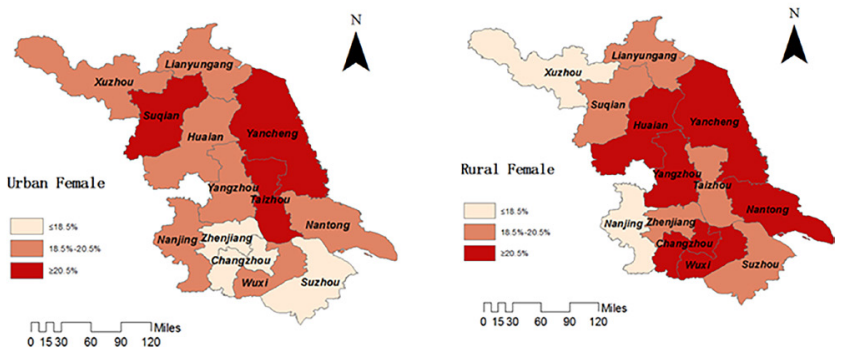

Figure 1 Regional distribution of screening elevated blood pressure among middle and high school students aged 1217 years in Jiangsu Province, 2017-2018. each city having two types of middle and high schools: one from the urban area and another from the rural area.

\section{Measurements}

Studies were conducted in 13 cities, including 13 urban districts and 13 rural counties. In every county or district we had at least one observer measuring height, at least one observer measuring weight, two to three observers measuring BP, two observers (one for boys and one for girls separately and secretly) investigating questions about first spermatorrhoea or menarche, and at least one observer responsible for receiving questionnaires and reviewing the quality of questionnaires. After physical examination students filled in a questionnaire, providing basic demographic information including name, sex, region, identification number, and habits of 1 week including smoking, alcohol consumption, sleep time, exposure to sunlight, and other health risk factors-related information such as family type, delivery mode, lifestyle habits and psychological test (Center for Epidemiological Studies-Depression, CES-D).

Anthropometric variables were measured by trained project members, skilled nurses and doctors. BP was measured using an upper arm automated BP device (Omron HBP-1300). Each participant was seated with the back supported, legs uncrossed and feet on the floor. The observers measured the circumference at the midpoint of the arm and selected an appropriate cuff, the width of which was as close as possible to $40 \%$ of the arm circumference. After each subject had rested for at least $15 \mathrm{~min}$, BP was measured on the left upper arm at the level of the heart 

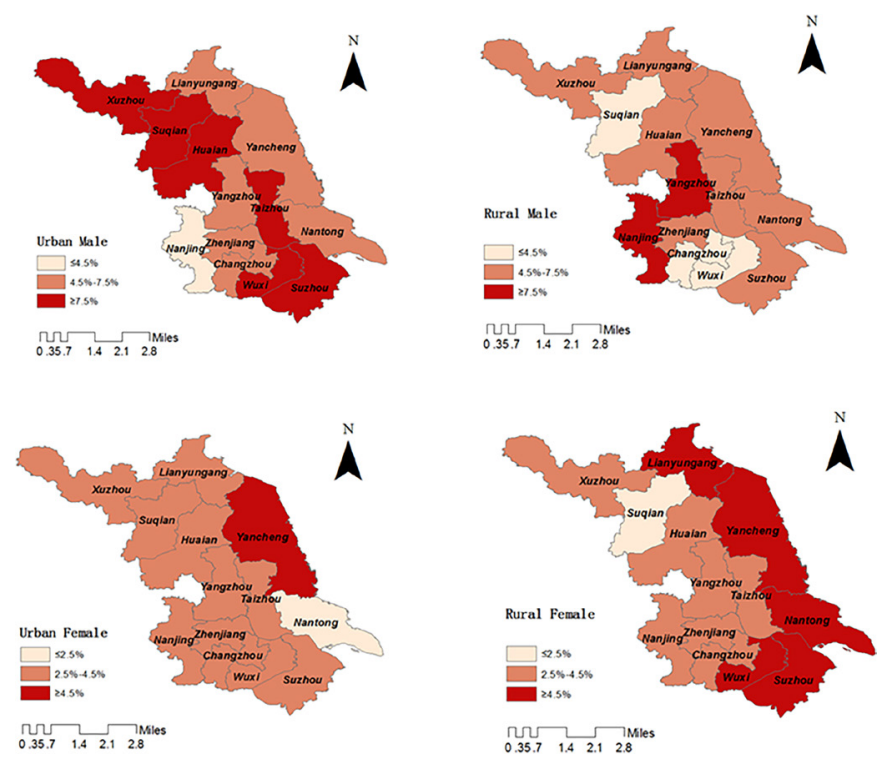

Figure 2 Regional distribution of obesity-related elevated blood pressure among middle and high school students aged 12-17 years in Jiangsu Province, 2017-2018.

with the lower arm passively supported. The interfacing two measurements were separated by at least 1 min intervals. Heart rate was recorded in beats/min at each visit. The start button was pressed and the measurements started automatically. ${ }^{12}$ Two observers were responsible for two measurements, and the average of the two BP measurements was recorded for each child.

Weight and height were measured after students had removed their shoes and clothes. Height (measured to the nearest $0.1 \mathrm{~cm}$ ) and weight (measured to the nearest $0.1 \mathrm{~kg}$ ) were measured using standardised equipment and procedures according to the health checklist for primary and junior school students (GB 16 134-2011; Chinese standard for physical examination records for elementary and middle school students). Body mass index (BMI) was calculated as weight in kilograms divided by height in metres squared.

All students filled in a questionnaire, providing basic demographic information including name, sex, region, identification number and so on. We reviewed students' habits of 1 week, including smoking, alcohol consumption, sleep time, exposure to sunlight, and health risk factors-related information such as family type, delivery mode and psychological test $\left(\right.$ CES-D $\left.{ }^{13}\right)$.

\section{Definitions of elevated BP}

We used the National Blood Pressure Reference for Chinese Han Children and Adolescents (CCBP) thresholds: $\geq 95$ th percentile as elevated BP (WS/T 610-2018; reference of screening for elevated BP among children and adolescents aged $7 \sim 18$ years; online supplementary table S1-S4). ${ }^{14}$

\section{Bias}

In this study, if our quality control observers found that the difference between systolic/diastolic BP is more than 10 $\mathrm{mm} \mathrm{Hg}$, the student will be required to go back to measure
Table 3 Age-specific obesity-related elevated blood pressure prevalence among middle and high school students aged 12-17 years in Jiangsu Province, 2017-2018

\begin{tabular}{ccc}
\hline Sex/Age & $\begin{array}{c}\text { Obesity prevalence } \\
\text { (95\% Cl) }\end{array}$ & $\begin{array}{c}\text { Obesity-related } \\
\text { hypertension* } \\
\text { prevalence } \\
\text { (95\% Cl) }\end{array}$ \\
\hline Female & $11.5(9.6$ to 13.3$)$ & $4.3(3.1$ to 5.5$)$ \\
\hline $12 \sim$ & $9.8(8.3$ to 11.2$)$ & $4.0(3.0$ to 4.9$)$ \\
\hline $13 \sim$ & $9.6(8.1$ to 11.1$)$ & $4.6(3.6$ to 5.7$)$ \\
\hline $14 \sim$ & $9.9(8.4$ to 11.3$)$ & $5.2(4.1$ to 6.3$)$ \\
\hline $15 \sim$ & $6.0(4.8$ to 7.2$)$ & $3.2(2.4$ to 4.1$)$ \\
\hline $16 \sim$ & $5.4(4.2$ to 6.6$)$ & $2.8(1.9$ to 3.7$)$ \\
\hline $17 \sim$ & $4.0(3.6$ to 4.4$)$ \\
\hline $12 \sim 17$ & $8.6(8.0$ to 9.2$)$ & \\
\hline Male & $17.9(15.7$ to 20.2$)$ & $5.1(3.8$ to 6.4$)$ \\
\hline $12 \sim$ & $15.5(13.7$ to 17.2$)$ & $6.9(5.7$ to 8.1$)$ \\
\hline $13 \sim$ & $14.0(12.3$ to 15.7$)$ & $6.9(5.7$ to 8.1$)$ \\
\hline $14 \sim$ & $15.2(13.4$ to 16.9$)$ & $7.3(6.1$ to 8.6$)$ \\
\hline $15 \sim$ & $12.7(11.1$ to 14.4$)$ & $6.3(5.1$ to 7.5$)$ \\
\hline $16 \sim$ & $12.8(11.1$ to 14.4$)$ & $7.4(6.1$ to 8.7$)$ \\
\hline $17 \sim$ & $14.5(13.8$ to 15.2$)$ & $6.7(6.2$ to 7.2$)$ \\
\hline $12 \sim 17$ & &
\end{tabular}

*Denotes the student is both obese and has elevated blood pressure.

a third BP. The observers responsible for BP measurement were blinded when the students received the third measurement. In addition, studies were stopped or rejected if subjects had arrhythmia and could not sit still for the study. Quality control methods and validation of Omron HBP-1300 can be found in Meng et $_{\text {al. }}{ }^{15}$

\section{Statistical analysis}

Descriptive statistics were used to summarise the variables concerning the characteristics of middle and high school students, and the prevalence was presented as the prevalence and $95 \%$ CI of the prevalence. Continuous variables such as BP were presented as mean with SD of the mean. Student's t-tests were used for comparisons of two groups with continuous variables, and $\chi^{2}$ tests were performed for comparing two proportions. Poisson regression analysis was performed and adjusted risk ratio values were computed to assess the relationship between hypertension and other risk factors. ${ }^{16-18}$ Data were analysed using SPSS V.20.0 software, and figures were drawn using ArcGIS V.10.0 software.

\section{Patient and public involvement (participants)}

Studies were conducted in 13 cities, including 13 urban districts and 13 rural counties. We randomly selected schools in each district or rural county, and then randomly sampled the students from each school. In each of the schools selected, teachers, students and doctors were included in this study. No patients were involved in this study. 
Table 4 Associations between risk factors and elevated blood pressure among middle and high school students aged 12-17 years

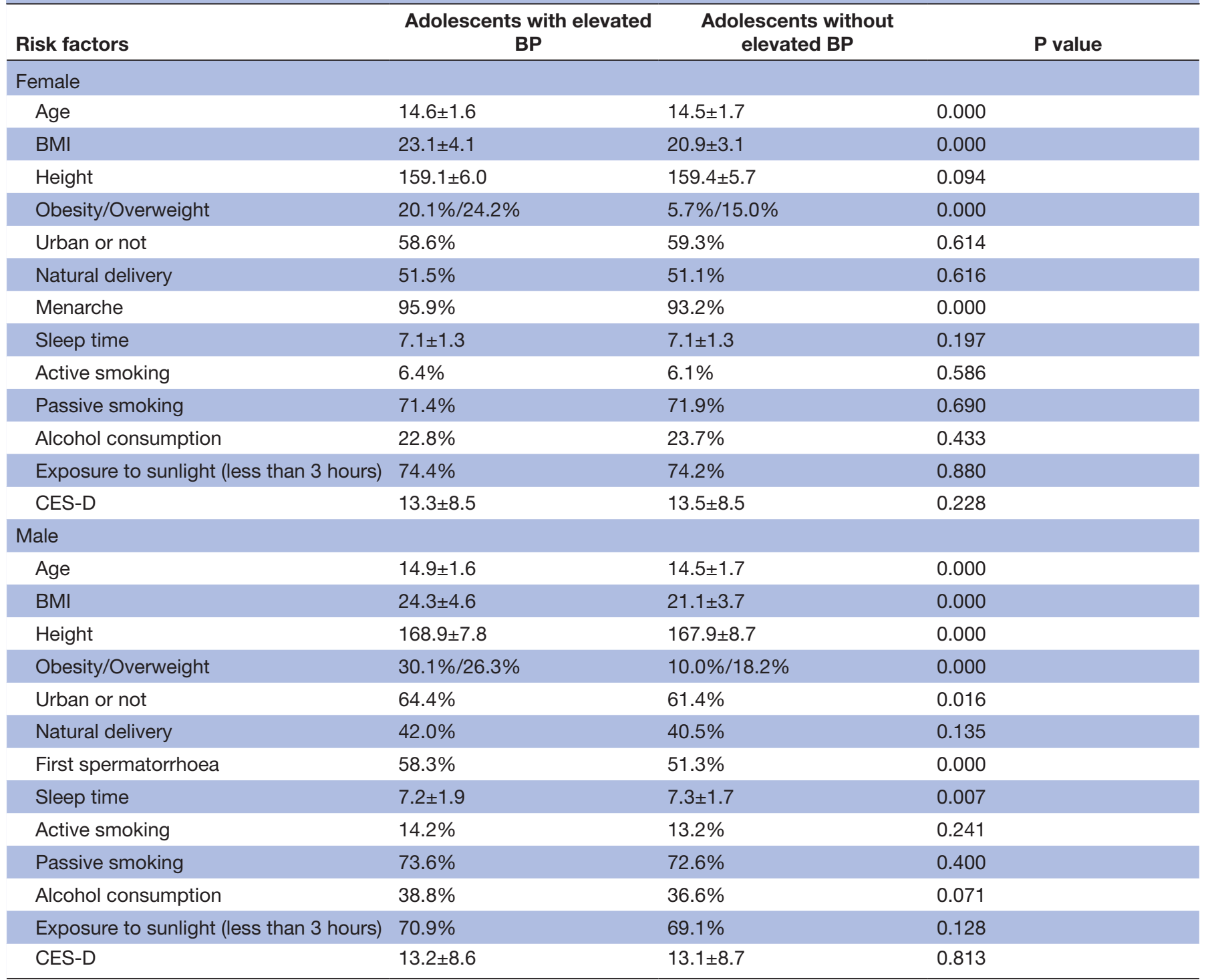

BMI, body mass index; BP, blood pressure; CES-D, Center for Epidemiological Studies-Depression.

\section{Ethics issues}

Reasons can be listed as follows: first, our study had no patients, did not involve extraction of biological materials such as blood, pleural effusion and cerebrospinal fluid (CSF) sampling, and had no experimental design. Second, this is our daily monitoring task to ensure students' health. The students and their parents were informed about the aim of the survey, and participants' and their parents' oral and written consent were obtained by teachers. Detailed information can be found in our previous study. ${ }^{11}$

\section{RESULTS}

\section{Participants}

The baseline characteristics of middle and high school students are shown in table 1 . The total number of students was 17 791, consisting of 8701 female students and 9090 male students, and the male to female ratio was 1.04. More than half of students were from urban regions: $59.1 \%$ of female students and $62.1 \%$ of male students. The results of physical examinations reveal that the values of BMI and diastolic blood pressure (DBP) are similar between male and female students. Height, weight and systolic BP (SBP) of male students are higher than female students. The proportion of menarche among female middle and high school students was $93.8 \%$, which is higher than that of the first spermatorrhoea among male middle and high school students (52.8\%). Nuclear family and extended family take up the major part of family type among middle and high school students. Self-reported survey showed that the proportion of natural delivery 
Table 5 Poisson regression analysis of the relationship between risk factors and elevated blood pressure

\begin{tabular}{|c|c|c|c|c|}
\hline Selected risk factors & $\beta$ & SE & $P$ value & Adjusted RR $(95 \% \mathrm{Cl})$ \\
\hline \multicolumn{5}{|l|}{ Female } \\
\hline Age & 0.029 & 0.015 & 0.051 & 1.029 (0.999 to 1.059$)$ \\
\hline Height & -0.006 & 0.004 & 0.134 & 0.994 (0.986 to 1.002$)$ \\
\hline Region & 0.030 & 0.028 & 0.286 & $1.030(0.975$ to 1.089$)$ \\
\hline Sleep duration & -0.021 & 0.018 & 0.247 & $0.979(0.946$ to 1.015$)$ \\
\hline Active smoking & -0.048 & 0.098 & 0.626 & $0.954(0.787$ to 1.155$)$ \\
\hline Passive smoking & 0.019 & 0.053 & 0.722 & $1.019(0.919$ to 1.131$)$ \\
\hline Exposure to sunlight & -0.007 & 0.055 & 0.893 & $0.993(0.891$ to 1.105$)$ \\
\hline \multicolumn{5}{|l|}{ Male } \\
\hline Region & 0.028 & 0.026 & 0.271 & 1.029 (0.978 to 1.082$)$ \\
\hline First spermatorrhoea & 0.223 & 0.045 & 0.000 & 1.250 (1.144 to 1.365$)$ \\
\hline Sleep duration & -0.032 & 0.013 & 0.018 & 0.969 (0.944 to 0.995$)$ \\
\hline Active smoking & -0.066 & 0.064 & 0.302 & $0.936(0.827$ to 1.061$)$ \\
\hline Passive smoking & -0.037 & 0.050 & 0.458 & 0.963 (0.873 to 1.063$)$ \\
\hline Exposure to sunlight & -0.065 & 0.049 & 0.180 & $0.937(0.851$ to 1.031$)$ \\
\hline
\end{tabular}

$\beta$, parameter estimate; BMI, body mass index; RR, risk ratio; SE, standard error of estimate.

among female and male students is $51.2 \%$ and $40.8 \%$, respectively, but $16.2 \%$ of female students and $27.5 \%$ of male students reported unknown delivery mode. The proportion of active smoking and passive smoking was $6.1 \%$ and $28.2 \%$ for female students and $13.4 \%$ and $27.2 \%$ for male students. The proportion of alcohol consumption for male students is higher than that of alcohol consumption for female students, but the proportion of exposure to sunlight less than 3 hours for female students is higher than that of exposure to sunlight less than 3 hours for male students. Sleep time for both male and female students is similar. The CES-D test score was also similar (table 1 ).

\section{Prevalence of screening elevated BP among students aged 12-17 years}

The prevalence of screening elevated BP for urban male middle and high school students was higher than that of elevated BP for rural male middle and high school students $(p<0.05)$. However, the prevalence of screening elevated BP for female students was similar between rural students and urban students $(p>0.05)$. Obesity-related elevated BP was similar for both female and male students between the rural region and urban region (figures 1 and 2).

The prevalence of screening elevated BP among students aged $12-17$ years was $20.0 \%$ (95\% CI $19.2 \%$ to $20.9 \%$ ) for female students and $22.3 \%$ (95\% CI $21.5 \%$ to $23.2 \%$ ) for male students. The average value for both SBP and DBP was within the normal reference range, and the prevalence of obesity-related elevated BP was $4.0 \%$ (95\% CI $3.6 \%$ to $4.4 \%$ ) for female students and $6.7 \%$ (95\% CI $6.2 \%$ to $7.2 \%)$ for male students (tables 2 and 3 ).

For female students, BMI, obesity/overweight and menarche can be risk factors contributing to elevated BP, and for male students BMI, obesity/overweight, first spermatorrhoea, sleep time and regional distribution can be risk factors contributing to elevated $\mathrm{BP}$ (table 4 ). In the Poisson regression analysis, BMI and menarche/first spermatorrhoea could be risk factors for elevated BP for both boys and girls (table 5).

\section{DISCUSSION}

In our study we investigated 17791 middle and high school students, consisting of 8701 female students and 9090 male students. Of the female students, $59.1 \%$ were from urban cities, while $62.1 \%$ of male students came from the urban region. The prevalence of elevated $\mathrm{BP}$ among students aged $12-17$ years was $20.0 \%$ (95\% CI $19.2 \%$ to $20.9 \%$ ) for female students and $22.3 \%$ (95\% CI $21.5 \%$ to $23.2 \%$ ) for male students. The prevalence of screening elevated BP for urban male middle and high school students was higher than that of elevated BP for rural male middle and high school students. However, similar phenomenon cannot be observed among female students. For both male and 
female students, BMI, obesity/overweight and menarche/ first spermatorrhoea can be risk factors contributing to elevated BP, and sleep time and regional distribution might be important factors that need to be investigated in depth.

The high prevalence of hypertension and poor hypertension control are serious problems in low-income and middle-income countries, ${ }^{19-22}$ and it has been reported that almost 2.1 million cardiovascular deaths and 1.2 million premature cardiovascular deaths were attributable to hypertension every year in China. ${ }^{23}$ The definition of hypertension in adults, which is based on the approximate level of BP that marks an increase in cardiovascular events and death, ${ }^{24}$ is not to be applied to children and adolescents. In this study, we used the CCBP reference based on a largescale representative population amounting to 0.2 million Han Chinese students. ${ }^{14}$ For national Chinese boys and girls aged $12-17$, the prevalence of hypertension ranged from $7.8 \%$ to $18.5 \%$ based on the CCBP reference, which was far lower than that in Jiangsu Province which ranged from $14.6 \%$ to $28.8 \%{ }^{14}$ The average height and proportion of obesity/overweight were higher than national levels, and CCBP reference values excluded obese/overweight children. We consider that CCBP reference values might not be appropriate for for children in Jiangsu Province. ${ }^{14}$ Also, we found that CCBP reference values are generally lower than the US reference values for older adolescents. ${ }^{25}$ The prevalence of hypertension in our study cannot be confirmed, but initial screening elevated BP shows results that are higher than the national results.

Generally, overweight and obese adolescents have higher than normal weights, and a strong relationship was observed between BMI and $\mathrm{BP}^{26}{ }^{27}$ In our study we also found this phenomenon. We found that the prevalence of obesity-related hypertension was high: $4.0 \%(3.6 \%-4.4 \%)$ for female students and $6.7 \%(6.2 \%-7.2 \%)$ for male students. An interesting phenomenon is that the prevalence of elevated $\mathrm{BP}$ in Jiangsu Province is similar to the rates of elevated BP seen in the USA, where we have nearly doubled the prevalence of overweight/obese (online supplementary figure S1). First, it is well worth noting that CCBP reference values are generally lower than the US reference values for older adolescents as mentioned before, making our prevalence higher than the actual values. ${ }^{25}$ Second, we used automated devices and initial measurements, which would also contribute to a higher prevalence of elevated BP.

Song $e t a l^{28}$ found that both boys and girls who enter puberty earlier with menarche/first spermatorrhoea were more likely to have high $\mathrm{BP}$, and combined with our results we also suggested that interventions focused on prepuberty students may be beneficial to reduce the prevalence of high BP. Dong et al $\mathrm{s}^{29}$ study revealed that short sleep duration may be one of the influential factors of high BP during puberty. In the USA, Sabanayagam and Shankar found that compared with a sleep duration of 7 hours, there was a positive association between both shorter and longer sleep durations, and they suggested that sleep duration may be an important marker of cardiovascular disease ${ }^{30}$ While in our study we found a weak association between sleep duration and elevated BP among boys, we still put sleep factor as an indispensable factor, and this problem should be explored in depth. In addition, the prevalence of hypertension varied geographically and economic status might play an important role. ${ }^{31}{ }^{32}$ Also, we observe the phenomenon that urban male middle and high school students had higher prevalence of elevated BP than rural male students, while the urban-rural gap in Jiangsu Province is narrowing.

Our study had some limitations. First, the US reference in 2004 recommended that hypertension should be defined using the results of elevated $\mathrm{BP}$ on at least three occasions in children and adolescents. In our study, we only had one BP measurement with two to three readings, and our results show increased prevalence of elevated BP on initial screening. Second, in this study we used self-reported questionnaire, and the results may not be entirely true. Completing questionnaires with the assistance of parents may improve accuracy, and this will be our next study. Third, the CCBP is based on an auscultatory method, while this study is done by automated devices. Even though some studies had been conducted to prove that the professional Omron HBP-1300 BP monitor meets the Association for the Advancement of Medical Instrumentation (AAMI) accuracy standards in Chinese children, ${ }^{15}$ consistency of measurement methods was not achieved. Also, it is known as referred before that regional distribution is an important factor, ${ }^{31}{ }^{32}$ and it may have an impact on the definition of childhood hypertension reference. Therefore, a new BP reference suitable for children from Eastern China is essential, and this will also be our next study.

\section{CONCLUSION}

We found that the burden of elevated BP for both female and male students aged 12-17 years in Jiangsu Province was substantially heavy (above the average level among Chinese adolescents). Potential risk factors can be BMI, obesity/overweight, menarche/first spermatorrhoea and sleep duration.

Contributors Data curation: XZ. Investigation: JY, WY. Methodology: YW. Project administration: WL. Software: LG. Article modification: RS, AW. Supervision: FZ, YZ. Writing the original draft: XZ, JY.

Funding This research was supported by the Demonstration Project of Comprehensive Prevention and Control of Emerging Infectious Diseases (BE2015714) http://www.jshealth.com/xxgk/sewcjz/xmzl/sbjkt/201708/ t20170830_59379.html. The funders had no role in study design, data collection and analysis, decision to publish, or preparation of the manuscript.

Map disclaimer The depiction of boundaries on the map(s) in this article do not imply the expression of any opinion whatsoever on the part of BMJ (or any member of its group) concerning the legal status of any country, territory, jurisdiction or area or of its authorities. The map(s) are provided without any warranty of any kind, either express or implied.

Competing interests None declared.

Patient consent for publication Obtained.

Ethics approval The study protocol was approved by the Institutional Review Board of Jiangsu Provincial Center for Disease Prevention and Control, while we were informed that approval by an ethical committee was not necessary. 
Provenance and peer review Not commissioned; externally peer reviewed.

Data availability statement All relevant data are within the paper and its supporting information files.

Open access This is an open access article distributed in accordance with the Creative Commons Attribution Non Commercial (CC BY-NC 4.0) license, which permits others to distribute, remix, adapt, build upon this work non-commercially, and license their derivative works on different terms, provided the original work is properly cited, appropriate credit is given, any changes made indicated, and the use is non-commercial. See: http://creativecommons.org/licenses/by-nc/4.0/.

\section{REFERENCES}

1. WHO. Global health risks: mortality and burden of disease attributable to selected major risks. 2013:1-63.

2. Satoh M, Ohkubo T, Asayama K, et al. Lifetime risk of stroke and coronary heart disease deaths according to blood pressure level: EPOCH-JAPAN (evidence for cardiovascular prevention from observational cohorts in Japan). Hypertension 2019;73:52-9.

3. Chen X, Wang Y. Tracking of blood pressure from childhood to adulthood a systematic review and Meta-Regression analysis. Circulation 2008;117:3171-80.

4. Toschke A, Kohl L, Mansmann U, et al. Meta-analysis of blood pressure tracking from childhood to adulthood and implications for the design of intervention trials. Acta Pã:'diatrica 2010;99:24-9.

5. Vik KL, Romundstad P, Nilsen TIL. Tracking of cardiovascular risk factors across generations: family linkage within the populationbased HUNT study, Norway. J Epidemiol Community Health 2013;67:564.

6. Erlingsdottir A, Indridason OS, Thorvaldsson O, et al. Blood pressure in children and target-organ damage later in life. Pediatric Nephrology 2010;25:323-8.

7. Wang J, Zhang L, Wang F, et al. Prevalence, awareness, treatment, and control of hypertension in China: results from a national survey. Am J Hypertens 2014;27:1355.

8. Gao Y, Chen G, Tian H, et al. Prevalence of hypertension in China: a cross-sectional study. PLoS One 2013;8:e65938.

9. Gooding HC, McGinty S, Richmond TK, et al. Hypertension awareness and control among young adults in the National longitudinal study of adolescent health. J Gen Intern Med 2014;29:1098-104.

10. Weiwei C, Du Wanliang JH, Weiping J, et al. Report on cardiovascular diseases in China 2013

11. Zhang X, Zhang F, Yang J, et al. Prevalence of overweight and obesity among primary school-aged children in Jiangsu Province, China, 2014-2017. PLoS One 2018;13:e0202681.

12. Lawes CM, Vander HS, Law MR, et al. Blood pressure and the global burden of disease 2000. Part 1: estimates of blood pressure levels. Journal of Hypertension 2006;24:423-30.

13. Brenner LA, Penzenik M. Center for epidemiological StudiesDepression. 2017.

15. Dong Y, Ma J, Song Y, et al. National blood pressure reference for Chinese Han children and adolescents aged 7 to 17 years. Hypertension 2017;70:897.
15. Meng L, Zhao D, Pan Y, et al. Validation of Omron HBP-1300 professional blood pressure monitor based on auscultation in children and adults. BMC Cardiovasc Disord 2016;16:9.

16. Petersen MR, Deddens JA. Re: "Easy SAS calculations for risk or prevalence ratios and differences". Am J Epidemiol 2006;163:1158-9.

17. Spiegelman D, Hertzmark E. Easy SAS calculations for risk or prevalence ratios and differences. Am J Epidemiol 2005;162:199-200.

18. McNutt L-A, Wu C, Xue X. Estimating the relative risk in cohort studies and clinical trials of common outcomes. Am J Epidemiol 2003;157:940-3.

19. Ibrahim MM, Damasceno AA. Ibrahim MM, Damasceno A. hypertension in developing countries. Lancet 2012;380:611-9.

20. Listed $\mathrm{N}$. The sixth report of the joint National Committee on prevention, detection, evaluation, and treatment of high blood pressure. Cardiology in Review 1998;6:272.

21. Mcalister FA, Campbell NRC, Zarnke K, et al. The management of hypertension in Canada: a review of current guidelines, their shortcomings and implications for the future. CMAJ : Canadian Medical Association journal = journal de l'Association medicale canadienne 2001;164:517-22.

22. Zanchetti A. WHO/ISH-Guidelines-Subcommittee: 1999 World health Organization-International Society of hypertension guidelines for the management of hypertension. Journal of Hypertension 1995;13.

23. He J, Gu D, Chen J, et al. Premature deaths attributable to blood pressure in China: a prospective cohort study. The Lancet 2009;374:1765-72.

24. Falkner B. Hypertension in children and adolescents: epidemiology and natural history. Pediatr Nephrol 2010;25:1219-24.

25. Yan W, Liu F, Li X, et al. Blood pressure percentiles by age and height for non-overweight Chinese children and adolescents: analysis of the China health and nutrition surveys 1991-2009. BMC Pediatr 2013;13:195

26. Lu X, Shi P, Luo C-Y, et al. Prevalence of hypertension in overweight and obese children from a large school-based population in Shanghai, China. BMC Public Health 2013;13:1-7.

27. Ferreira JS, Aydos RD. [Prevalence of hypertension among obese children and adolescents]. Ciência \& Saúde Coletiva 2010;15:97-104

28. Song Y, Ma J, Zhang B, et al. [The combined effect of spermarche, menarche and obesity on elevated blood pressure among Chinese students]. Zhonghua Yu Fang Yi Xue Za Zhi 2017;51:306-12.

29. Dong $\mathrm{B}$, Wang $\mathrm{H}$-jun, Ma J. [Association between sleep duration and puberty blood pressure among students aged 9 to 17 years in China]. Zhonghua Yu Fang Yi Xue Za Zhi 2013;47:718.

30. Sabanayagam C, Shankar A. Sleep duration and cardiovascular disease: results from the National health interview survey. Sleep 2010;33:1037.

31. Li D, Lv J, Liu F, et al. Hypertension burden and control in mainland China: analysis of nationwide data 2003-2012. Int J Cardiol 2015;184:637.

32. Wu Y, Huxley R, Li L, et al. Prevalence, awareness, treatment, and control of hypertension in China: data from the China national nutrition and health survey 2002. Circulation 2008;118:2679. 